\title{
SORÇÃo E DEsSORÇÃo do Ametryn em LAtossolos BRASIleIROS ${ }^{1}$
}

\author{
Sorption and Desorption of Ametryn in Brazilian Latosols
}

\author{
SILVA, L.O.C. ${ }^{2}$, SILVA, A.A. ${ }^{3}$, D’ANTONINO, L. ${ }^{4}$, QUEIROZ, M.E.L.R. ${ }^{5}$, LIMA, C.F. ${ }^{5}$ e \\ FREITAS, F.C.L. ${ }^{6}$
}

\begin{abstract}
RESUMO - O conhecimento dos processos de retenção de herbicidas em solo é fundamental para se prever o potencial de lixiviação e degradação e a eficiência no controle das plantas daninhas. Objetivou-se com este trabalho avaliar os processos de sorção e dessorção do ametryn em quatro solos brasileiros: Latossolo Vermelho-Amarelo (LVA), Latossolo VermelhoAmarelo húmico (LVAh), Latossolo Vermelho (LV) e Latossolo Amarelo (LA), com diferentes valores de pH. Para isso, utilizou-se o método Batch Equilibrium em condições controladas de laboratório e análise por cromatografia liquida de alta eficiência, com detector UV-Vis a $245 \mathrm{~nm}$. Considerando os valores da constante de Freundlich modificada ( $\left.\mathrm{K}_{\mathrm{f}}^{\prime}\right)$, verificou-se, entre os solos estudados, a ordem crescente de sorção do ametryn: LV pH 6,06 < LV pH 5,00 $<$ LA pH 6,30 < LVA pH 6,11 < LVA pH 5,40 < LVAh pH 6,24<LVAh pH 4,8. Conclui-se que as caracteristicas teor de matéria orgânica e pH dos solos estudados afetaram a sorção e a dessorção do ametryn. Verificou-se também que solos com maiores teores de matéria orgânica foram os que apresentaram as maiores taxas de sorção, além das menores porcentagens de dessorção, indicando a ocorrência de histerese.
\end{abstract}

Palavras-chave: herbicida, solo, batch equilibrium, cromatografia líquida, isotermas de Freundlich.

\begin{abstract}
Knowledge of herbicide retention processes in soil is fundamental to predict leaching potential, degradation, and weed control efficiency. The objective of this study was to evaluate the processes of sorption and desorption of ametryn in four Brazilian soils: Red-Yellow Latosol (LVA), Red-Yellow humic Latosol (LVAh), Red Latosol (LV), and Yellow Latosol (LA), with different pH values. Thus, the method "Batch Equilibrium" was applied under controlled laboratory conditions, and analysis by high performance liquid chromatography using UV-Vis detector at $245 \mathrm{~nm}$. Considering the values of the modified Freundlich constant ( $K$ ' $f$ ), the following increasing sorption order of ametryn was verified: $L \mathrm{VpH} 6.06<5.00 \mathrm{LV} \mathrm{pH}<6.30 \mathrm{LA} \mathrm{pH}<6.11 \mathrm{pH} L \mathrm{LA}<L V A 5.40 \mathrm{pH}$ $<6.24 \mathrm{pH} L V A h<L V A h \mathrm{pH}$ 4.8. It was concluded that the organic matter content characteristics and the $\mathrm{pH}$ of the soils affected ametryn sorption and desorption, and that soils with higher organic matter content showed the highest rates of sorption, besides smaller percentages of desorption, indicating the occurrence of hysteresis.
\end{abstract}

Keywords: herbicide, soil, batch equilibrium, liquid chromatography, Freundlich isotherms

\section{INTRODUÇÃO}

O uso de herbicidas sem os conhecimentos básicos de suas interações com o solo e clima representa alto risco de contaminação ambiental e redução da biodiversidade. Nesse sentido, o conhecimento dos processos de retenção dessas moléculas pelo solo é fundamental para prever o potencial de lixiviação, degradação e a eficiência no controle das plantas daninhas quando um herbicida atinge o solo.

Recebido para publicação em 29.5.2011 e aprovado em 29.1.2012.

2 D.Sc., Professora do Núcleo de Química, Instituto Federal de Educação Ciência e Tecnologia do Sudeste de Minas, Campus Barbacena - IFSUDESTEMG; ${ }^{3}$ D.Sc., Professor Associado, Departamento de Fitotecnia, Universidade Federal de Viçosa DFT/UFV; ${ }^{4}$ Engo-Agr ${ }^{\circ}$, D.Sc., DFT/UFV; ${ }^{5}$ D.Sc., Professor Associado, Departamento de Química, DEQ/UFV; ${ }^{6}$ D.Sc., Professor Adjunto, Departamento de Ciências Vegetais, Universidade Federal Rural do Semi-Árido - UFERSA.

Planta Daninha, Viçosa-MG, v. 30, n. 3, p. 633-640, 2012 
Cada herbicida possui um conjunto de propriedades que interferem no destino que essas moléculas terão no ambiente (McDonald et al., 1999), e a intensidade da sua sorção em solos determinará a disponibilidade das moléculas às plantas e microrganismos, controlará sua movimentação para as camadas mais profundas do solo e também para as águas subterrâneas (Herwig et al., 2001). Como consequência, a eficácia de controle das plantas daninhas e o risco de contaminação ambiental por esses compostos também são afetados (Ferri et al., 2005).

Além da constante de sorção, o tempo que um herbicida leva para ser adsorvido pelos coloides do solo é importante no manejo de plantas daninhas, e chuvas logo após a aplicação podem promover maior intoxicação à cultura, lixiviação e escorrimento superficial dos herbicidas (Albuquerque et al., 2001).

Para interpretação dos processos de sorção de diferentes substâncias em diversos tipos de solo, utiliza-se com frequência a equação de Freundlich $\left(\mathrm{C}_{\mathrm{s}}=\mathrm{K}_{\mathrm{f}} \mathrm{C}_{\mathrm{e}}{ }^{1 / \mathrm{n}}\right)$ (Lovell et al., 2000; Koskinen et al., 2006; Akma et al., 2009), a qual fornece os coeficientes de sorção, sendo $\mathrm{K}_{\mathrm{f}}$ e $1 / \mathrm{n}$ constantes empíricas que representam a capacidade e intensidade de sorção, respectivamente.

Todavia, o uso dos coeficientes dessa equação para comparação da capacidade sortiva tem sido questionado, uma vez que, na sua análise dimensional, observa-se que a unidade da constante $\mathrm{K}_{\mathrm{f}}$ varia de forma não linear com o valor de 1/n (Bowman, 1982; Carmo et al., 2000; Chiou et al., 2000). As variações na unidade da constante de Freundlich tornam inviável a comparação do processo de sorção de herbicidas em solos com diferentes características físico-químicas e de diferentes localidades.

Uma proposta para tornar a unidade de $\mathrm{K}_{\mathrm{f}}$ independente do valor de $1 / \mathrm{n}$ foi apresentada por Carmo et al. (2000), qual consiste em normalizar $\mathrm{C}_{\mathrm{e}}$ utilizando o valor da solubilidade em água $\left(\mathrm{S}_{\mathrm{w}}\right)$ de um dado composto $\left(\mathrm{C}_{\mathrm{r}}=\right.$ $\left.\mathrm{C}_{\mathrm{e}} / \mathrm{S}_{\mathrm{w}}\right)$. Com isso, a equação de Freundlich pode ser escrita de forma modificada $(\mathrm{Cs}=$ $\mathrm{K}_{\mathrm{f}} \mathrm{C}_{\mathrm{r}}{ }^{1 / \mathrm{n}}$ ), sendo atualmente utilizada por diferentes autores no estudo de processos de sorção de compostos orgânicos em diferentes matrizes (Nguyen et al., 2004; Wang et al., 2007; Tang et al., 2009).

O processo de dessorção dos herbicidas, em muitos casos, não corresponde à ordem decrescente de sua sorção, e as razões para esse fato ainda não são totalmente compreendidas, podendo ser de natureza termodinâmica ou cinética, ou ambas (Chefetz et al., 2004). Os mecanismos atuantes nos processos sortivos e dessortivos são distintos nos solos e sua compreensão não depende somente dos coeficientes de sorção, mas também da forma como cada composto interage na superficie adsorvente (Vivian et al., 2007).

Devido ao grande uso do ametryn na cultura de cana-de-açúcar no Brasil, em solos com diferentes características físicas e químicas, sem conhecimento de suas interações com esses tipos de solo, têm-se observado sérios problemas de controle ineficiente das plantas daninhas, intoxicação de culturas e contaminação de águas superficiais e subterrâneas (Oliveira \& Freitas, 2009; Carvalho et al., 2010). Neste trabalho, objetivou-se quantificar a sorção e a dessorção do ametryn em quatro solos brasileiros, com valores de $\mathrm{pH}$ natural e corrigido, visando gerar informações para desenvolver modelos matemáticos de predição do comportamento desse herbicida em solos brasileiros.

\section{MATERIAL E MÉTODOS}

Amostras dos solos foram coletadas nas profundidades de 0 a $20 \mathrm{~cm}$, em diferentes locais, sem histórico de aplicação do ametryn, sendo um Latossolo Amarelo (LA) do municipio de Sooretama-ES, em área de cafezal abandonado; um Latossolo Vermelho-Amarelo (LVA) do município de Viçosa, MG, em área de pastagem degradada; um Latossolo VermelhoAmarelo húmico (LVAh) do município de Viçosa, MG, em área de mata atlântica; e um Latossolo Vermelho (LV) do municipio de Três Marias, MG, em área de cultura de eucalipto. As características químicas e físicas dos solos estudados estão apresentadas nas Tabelas 1 e 2, respectivamente.

$\mathrm{O}$ pH dos solos foi corrigido para valores próximos de 6,0, com base em curvas de neutralização geradas para as diferentes matrizes. A partir dessa etapa, trabalhou-se com os solos 
Tabela 1 - Resultados das análises químicas das amostras de Latossolo Vermelho-Amarelo (LVA), Latossolo Vermelho-Amarelo húmico (LVAh), Latossolo Vermelho (LV) e Latossolo Amarelo (LA)

\begin{tabular}{|c|c|c|c|c|c|c|c|c|c|c|c|c|c|}
\hline \multirow{2}{*}{ Solo } & \multirow{2}{*}{$\begin{array}{c}\mathrm{pH} \\
\left(\mathrm{H}_{2} \mathrm{O}\right)\end{array}$} & $\mathrm{P}$ & $\mathrm{K}$ & $\mathrm{Ca}$ & $\mathrm{Mg}$ & $\mathrm{Al}$ & $\mathrm{H}+\mathrm{Al}$ & SB & $(\mathrm{t})$ & $(\mathrm{T})$ & $\mathrm{V}$ & $\mathrm{m}$ & \multirow{2}{*}{$\begin{array}{c}\mathrm{MO} \\
\left(\mathrm{Dag} \mathrm{kg}^{-1}\right)\end{array}$} \\
\hline & & \multicolumn{2}{|c|}{$\left.(\mathrm{mg} \mathrm{dm})^{-3}\right)$} & \multicolumn{7}{|c|}{$\left(\mathrm{cmol}_{\mathrm{c}} \mathrm{dm}^{-3}\right)$} & \multicolumn{2}{|c|}{$(\%)$} & \\
\hline LVA & 5,4 & 3,5 & 50 & 0,8 & 0,3 & 0,8 & 8,91 & 1,38 & 2,18 & 10,29 & 13 & 37 & 3,7 \\
\hline LVAh & 4,8 & 2,0 & 46 & 0,6 & 0,7 & 1,4 & 10,73 & 1,42 & 2,82 & 12,15 & 12 & 50 & 4,3 \\
\hline LV & 5,0 & 0,8 & 14 & 0,2 & 0,0 & 0,4 & 3,30 & 0,24 & 0,64 & 3,54 & 7 & 63 & 0,8 \\
\hline LA & 6,3 & 9,6 & 110 & 2,9 & 1,0 & 0,0 & 1,32 & 4,18 & 4,18 & 5,50 & 76 & 0 & 2,2 \\
\hline
\end{tabular}

Tabela 2 - Resultados das análises físicas das amostras de Latossolo Vermelho-Amarelo (LVA), Latossolo Vermelho-Amarelo húmico (LVAh), Latossolo Vermelho (LV) e Latossolo Amarelo (LA)

\begin{tabular}{|l|c|c|c|c|c|}
\hline \multirow{2}{*}{ Solo } & Areia Grossa & Areia Fina & Silte & Argila & Classe textural \\
\cline { 2 - 6 } & \multicolumn{5}{|c|}{$\left(\mathrm{dag} \mathrm{kg}^{-1}\right)$} \\
\hline LVA & 15 & 12 & 4 & 69 & Muito Argiloso \\
\hline LVAh & 23 & 13 & 5 & 59 & Muito Argiloso \\
\hline LV & 36 & 36 & 1 & 27 & Franco-Argiloarenoso \\
\hline LA & 60 & 19 & 1 & 20 & Franco-Arenoso \\
\hline
\end{tabular}

nas seguintes condições: LVA pH 5,40, LVA pH 6,11, LVAh pH 4,8, LVAh pH 6,24, LV pH 5,00, LV pH 6,06 e LA pH 6,30.

A solução-estoque do herbicida foi preparada a partir do padrão, com $98,3 \%$ de pureza, solubilidade de $200 \mathrm{mg} \mathrm{L}^{-1}\left(22{ }^{\circ} \mathrm{C}\right)$, pKa de 4,1 e $\log \mathrm{K}_{\mathrm{ow}}$ de 2,63 (Rodrigues \& Almeida, 2005), na concentração de $1.000 \mu \mathrm{g} \mathrm{mL}^{-1} \mathrm{em}$ acetonitrila. As soluções de trabalho foram preparadas em solução aquosa de $\mathrm{CaCl}_{2}$ $0,01 \mathrm{~mol} \mathrm{~L}^{-1}$, a partir da diluição da soluçãoestoque. A determinação do tempo necessário de equilíbrio da sorção do ametryn nos solos foi feita pelo método batch equilibrium (OECD, 2000), que consiste em adicionar $10,0 \mathrm{~mL}$ de uma solução de ametryn $10,0 \mathrm{mg} \mathrm{L}^{-1}$, preparada em $\mathrm{CaCl}_{2}$ 0,01 $\mathrm{mol} \mathrm{L}^{-1}$, em tubos de polipropileno contendo amostras de 2,00 g de solo. Esses tubos foram colocados sob agitação vertical em diferentes intervalos de tempo $(0,5$, $1,2,3,4,8,12,16,20$ e 24 horas) em temperatura ambiente $\left(25 \pm 2{ }^{\circ} \mathrm{C}\right)$. Após agitação, as amostras foram centrifugadas a $2.260 \mathrm{~g}$, por sete minutos. Parte do sobrenadante foi filtrada em membrana PTFE de $0,45 \mu \mathrm{m}$ para vials de $1,5 \mathrm{~mL}$, os quais foram submetidos à análise por cromatografia líquida de alta eficiência (CLAE).

A avaliação da sorção do ametryn nos solos foi efetivada utilizando soluções de trabalho preparadas a partir da solução-estoque nas concentrações de 0,$0 ; 5,0 ; 10,0 ; 25,0 ; 50,0$; e $100,0 \mathrm{mg} \mathrm{L}^{-1}$ do herbicida em $\mathrm{CaCl}_{2}$ 0,01 $\mathrm{mol} \mathrm{L}^{-1}$. Adicionaram-se 10,0 mL dessas soluções em tubos de polipropileno contendo 2,00 g de solo, os quais foram colocados sob agitação vertical em temperatura ambiente pelo tempo de equilíbrio determinado. Após agitação, as amostras foram centrifugadas a $2.260 \mathrm{~g}$ por sete minutos. O sobrenadante foi retirado e filtrado em membrana de $0,45 \mu \mathrm{m}$ diretamente em vials de $1,5 \mathrm{~mL}$ de capacidade, para posterior análise cromatográfica.

Nos estudos de dessorção foram utilizados tubos do ensaio de sorção que continham $100,0 \mathrm{mg} \mathrm{L}^{-1}$ de ametryn, os quais tiveram seu sobrenadante totalmente retirado. A esses tubos foi adicionado o mesmo volume de solução $(10,0 \mathrm{~mL})$ de $\mathrm{CaCl}_{2} 0,01 \mathrm{~mol} \mathrm{~L}^{-1}$, isenta de herbicida. Os tubos foram fechados, agitados em misturador vórtex por 10 segundos e submetidos a agitação vertical por 12 horas, em temperatura ambiente de $25 \pm 2{ }^{\circ} \mathrm{C}$. As etapas de retirada de $1,0 \mathrm{~mL}$ do sobrenadante, reposição do volume retirado, nova suspensão da mistura solo-solução e novo estabelecimento de equilíbrio sob agitação foram repetidas três vezes: 12,24 e 36 horas, consecutivamente. O sobrenadante recolhido foi filtrado com membrana de $0,45 \mu \mathrm{m}$ diretamente em vials de $1,5 \mathrm{~mL}$ e analisado por CLAE. 
A determinação quantitativa do ametryn foi feita utilizando-se um sistema de cromatografia líquida de alta eficiência, modelo Shimadzu LC 20AT, com detector UV-Vis (Shimadzu SPD 20A), e coluna $\mathrm{C}_{18}$ de aço inox (Shimadzu VP- ODS Shim-pack $150 \mathrm{~mm}$ $\mathrm{x} 4,6 \mathrm{~mm}$ diâmetro interno). As condições cromatográficas de análise foram otimizadas a partir de trabalhos realizados por Andrade et al. (2010), as quais consistiram em: fase móvel composta por água e acetonitrila na proporção de 70:30 (v/v), acidificada com 0,02\% de ácido

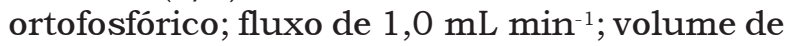
injeção de $20 \mu \mathrm{L}$; comprimento de onda de $245 \mathrm{~nm}$; e tempo de retenção de aproximadamente 5,5 minutos. A quantificação foi realizada por meio da comparação das áreas obtidas nos cromatogramas em cada ensaio, pelo método de calibração externa, e identificação, pelo tempo de retenção, através de um padrão analítico do ametryn.

A quantidade de herbicida sorvida ao solo $\left(C_{\mathrm{s}}\right)$ foi calculada em $\mathrm{mg} \mathrm{kg}^{-1}$ por diferença entre a quantidade presente em uma soluçãopadrão inicialmente adicionada ao solo $\left(\mathrm{C}_{\mathrm{p}}\right)$, em $\mathrm{mg} \mathrm{L}^{-1}$, e a quantidade encontrada na solução de equilíbrio $\left(C_{e}\right)$, em $\mathrm{mg} \mathrm{L}^{-1}$. Na interpretação do processo sortivo utilizou-se a equação de Freundlich modificada.

Para determinar as concentrações de ametryn nas soluções de dessorção em $\mathrm{mg} \mathrm{L}^{-1}$, tomou-se como base a quantidade $\left(\mathrm{mg} \mathrm{kg}^{-1}\right)$ do herbicida que permaneceu sorvida ao solo após cada passo de dessorção e calculou-se a diferença entre a concentração do herbicida no solo antes das etapas de dessorção e a concentração na solução analisada após cada intervalo avaliado. Em seguida, calculou-se a porcentagem de dessorção a cada nível de diluição. Todos os ensaios foram realizados em triplicata, e os dados obtidos, submetidos à análise de regressão, sendo os coeficientes das equações testados pelo teste t a $5 \%$ de significância.

\section{RESULTADOS E DISCUSSÃO}

Em todos os solos avaliados, observou-se que o tempo de equilíbrio das estimativas das curvas de cinética de sorção do ametryn foi semelhante (Figura 1). Após oito horas de agitação, verificou-se que a concentração na solução em contato com o solo atingiu o equilibrio; no entanto, optou-se por trabalhar com o tempo de 12 horas, visando garantir o estabelecimento desse equilíbrio em todos os solos estudados.

As estimativas das isotermas de Freundlich normalizadas da sorção de ametryn nos diferentes solos encontram-se na Figura 2. Comparando as isotermas e os parâmetros de Freundlich, $\mathrm{K}_{\mathrm{f}}$ e $1 / \mathrm{n}$ (Tabela 3), observou-se que os coeficientes de determinação das equações variaram entre 0,93 e 0,99, evidenciando bom ajuste do modelo aos dados, e que o parâmetro ajustado $1 / \mathrm{n}$ apresentou valores menores que 1 , variando entre 0,34 e 0,78 , o que caracteriza isotermas do tipo $\mathrm{L}$, as quais possuem inclinação não linear e côncava em relação à abscissa, havendo diminuição da disponibilidade dos sítios de sorção quando a concentração da solução aumenta (Falone \& Vieira, 2004).

A variação no valor do coeficiente $1 / \mathrm{n}$ indica que o processo de sorção do ametryn nos

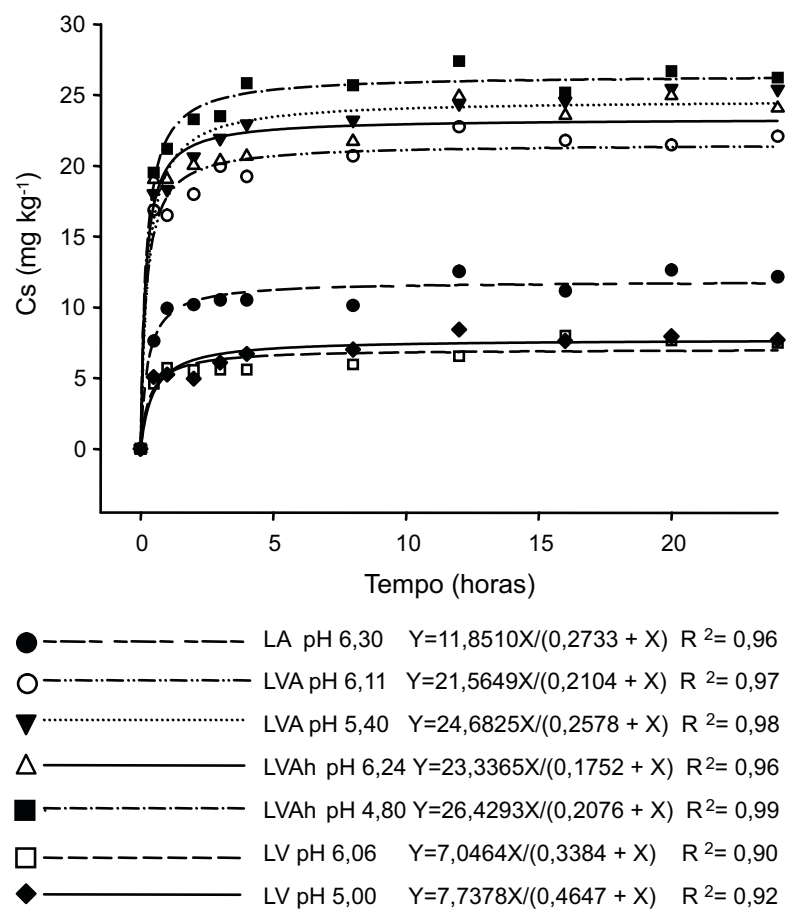

Figura 1 - Estimativas das curvas de cinética de sorção para ametryn em Latossolo Vermelho-Amarelo (LVA), Latossolo Vermelho-Amarelo húmico (LVAh), Latossolo Vermelho (LV) e Latossolo Amarelo (LA), com diferentes valores de $\mathrm{pH}$. 

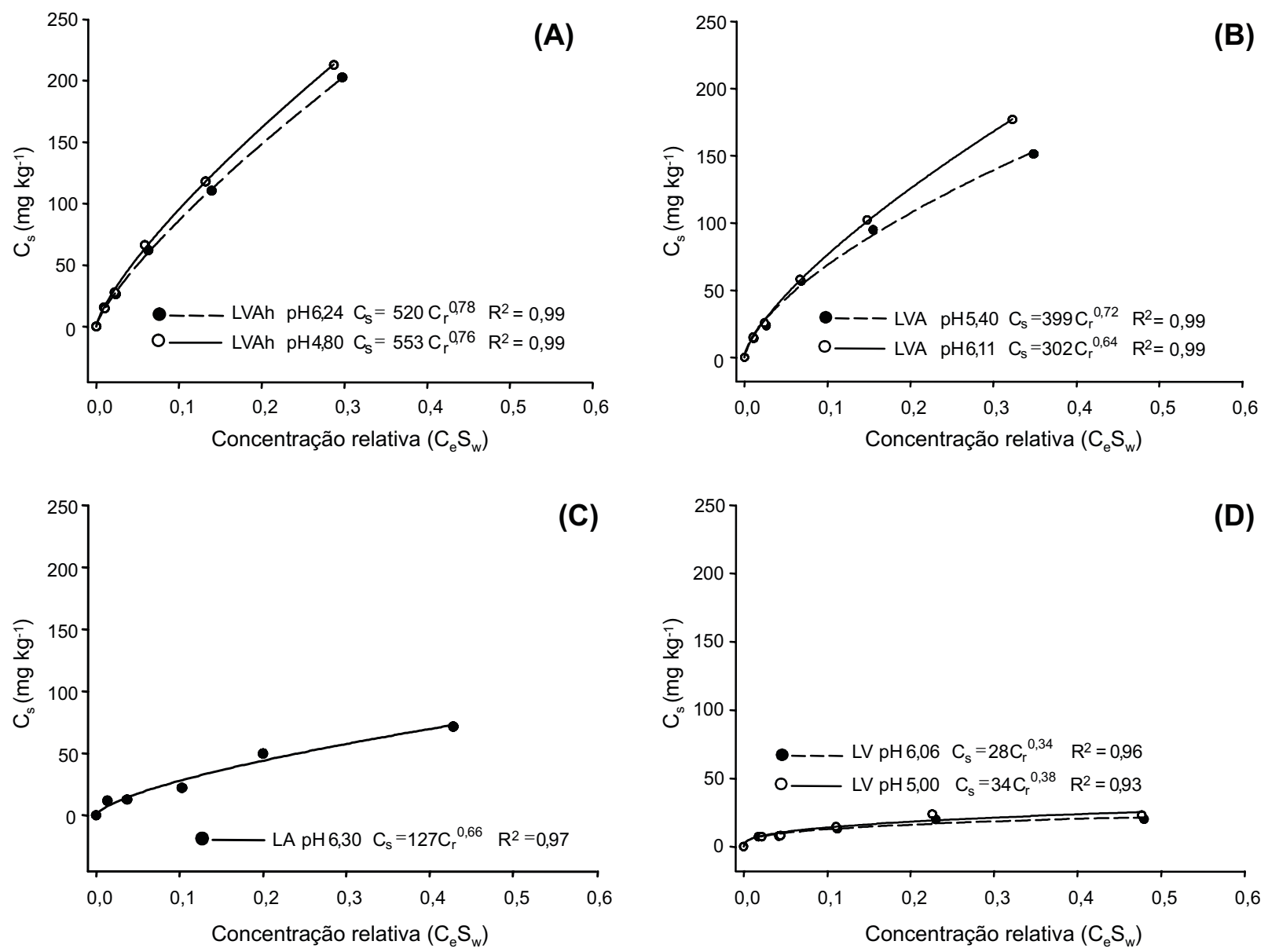

Figura 2 - Estimativas das isotermas de sorção do ametryn em (A) Latossolo Vermelho-Amarelo húmico (LVAh), (B) Latossolo Vermelho-Amarelo (LVA), (C) Latossolo Amarelo (LA) e (D) Latossolo Vermelho (LV), com diferentes valores de $\mathrm{pH}$.

Tabela 3 - Parâmetros de Freundlich modificados para a sorção de ametryn em Latossolo Vermelho-Amarelo (LVA), Latossolo Vermelho-Amarelo húmico (LVAh), Latossolo Vermelho (LV) e Latossolo Amarelo (LA)

\begin{tabular}{|c|c|c|c|c|c|c|c|}
\hline \multicolumn{10}{|c|}{ Solo } \\
\hline Coeficiente & $\begin{array}{c}\text { LVA } \\
\mathrm{pH} 5,40\end{array}$ & $\begin{array}{c}\text { LVA } \\
\mathrm{pH} \mathrm{6,11}\end{array}$ & $\begin{array}{c}\text { LVAh } \\
\mathrm{pH} \mathrm{4,80}\end{array}$ & $\begin{array}{c}\text { LVAh } \\
\mathrm{pH} \mathrm{6,24}\end{array}$ & $\begin{array}{c}\text { LV } \\
\mathrm{pH} \mathrm{5,00}\end{array}$ & $\begin{array}{c}\text { LV } \\
\mathrm{pH} 6,06\end{array}$ & $\begin{array}{c}\text { LA } \\
\mathrm{pH} 6,30\end{array}$ \\
\hline $\mathrm{K}_{\mathrm{f}}^{\prime}$ & 399 & 302 & 553 & 520 & 34 & 28 & 127 \\
\hline $1 / \mathrm{n}$ & 0,72 & 0,64 & 0,76 & 0,78 & 0,34 & 0,38 & 0,66 \\
\hline $\mathrm{R}^{2}$ & 0,99 & 0,99 & 0,99 & 0,99 & 0,93 & 0,96 & 0,97 \\
\hline
\end{tabular}

solos avaliados ocorre de forma não linear e com intensidade diferente para as diferentes matrizes estudadas, justificando o uso da equação de Freundlich modificada proposta por Carmo et al. (2000).

Os valores de $\mathrm{K}_{\mathrm{f}}$ refletem parcialmente a capacidade de movimento e persistência de um composto no ambiente. Considerando os valores obtidos (Tabela 3), pode-se inferir que a matriz de solo com maior sorção foi o LVAh pH 4,80, seguido por LVAh pH 6,24; LVA pH 5,40; LVA pH 6,11; LA pH 6,30; LV pH 5,00; e LV pH 6,06 .

Os solos LVA e LVAh apresentaram maiores teores de matéria orgânica e argila, enquanto o LV e o LA, os menores (Tabelas 1 e 
2), o que explica a menor sorção obtida nestes últimos. Quanto ao LV, foram encontrados menores valores de $\mathrm{K}_{\mathrm{f}}$ associados a baixos valores de $1 / \mathrm{n}$, evidenciando afastamento da linearidade das isotermas referentes a esse solo e reafirmando a baixa capacidade sortiva dele.

A matéria orgânica apresenta grande influência nos processos de sorção de herbicidas bases fracas em solos (Oliveira Jr. et al., 2001; Wauchope et al., 2002). Em geral, quanto mais alto o teor de matéria orgânica, maior será a sorção do herbicida e, com isso, menor o potencial de lixiviação (Rossi et al., 2005).

Dick et al. (2010), estudando a influência da matéria orgânica na sorção de atrazine em amostras de solos representativos da região Sul do Brasil, reportaram que, mesmo presente em quantidades relativamente pequenas, entre 1,2 e 3,3 dag $\mathrm{kg}^{-1}$, esse constituinte foi o principal sorvente, contribuindo com mais de $56 \%$ na sorção do herbicida nos solos avaliados. No presente trabalho, quando se comparou a sorção do ametryn nos diferentes solos, observou-se relação positiva entre a sorção e o teor de matéria orgânica deles (Tabela 1).

Quando se compararam os valores da sorção do ametryn nos diferentes solos, com e sem correção de $\mathrm{pH}$, foram observados valores inversos entre $\mathrm{pH}$ e sorção, ou seja, o aumento no pH implicou diminuição da sorção do herbicida no solo, evidenciando o risco de lixiviação do produto. Maior coeficiente de sorção foi observado no LVAh $\mathrm{pH} 4,80$, cujo valor de $\mathrm{pH}$ se encontrava mais próximo ao $\mathrm{pKa}$ do herbicida $(4,1)$. Isso pode ser explicado pelo fato de herbicidas bases fracas, como o ametryn, encontrarem-se predominantemente na forma protonada em solos com valores de $\mathrm{pH}$ abaixo de seu pKa (Oliveira Jr. et al., 2001). Quanto menor o $\mathrm{pH}$ da solução em relação ao pKa do ametryn, maior número de moléculas passou a apresentar carga líquida positiva com o aumento da atração elétrica entre os cátions do herbicida e as cargas negativas das partículas do solo (Sheng et al., 2005), o que pode favorecer sua sorção.

As porcentagens acumuladas de dessorção a 12,24 e 36 horas são apresentadas na Figura 3. Observa-se que o processo de dessorção foi maior no LV com e sem correção de $\mathrm{pH}$, o qual apresentou menor teor de matéria orgânica, favorecendo a liberação do herbicida sorvido. Os demais solos apresentaram baixas porcentagens de dessorção, evidenciando que o processo de dessorção é mais lento que o de sorção. A liberação pelo solo de apenas parte das moléculas anteriormente sorvidas caracteriza o fenômeno denominado histerese, ou seja, resistência à dessorção.

Vivian et al. (2007) avaliaram a capacidade de sorção e dessorção do ametryn em seis solos brasileiros e observaram maior capacidade de sorção em solos com elevados teores de matéria orgânica e argila, além de correlações positivas com características relacionadas à maior capacidade de retenção de água e elevada área superficial específica para os solos com teores de argila e matéria orgânica elevados, o que pode comprometer a eficiência do ametryn em solos bastante argilosos e com elevado conteúdo de matéria orgânica. Já em solos pobres em matéria orgânica e com elevada dessorção, pode ocorrer a lixiviação do herbicida para águas superficiais e subterrâneas.

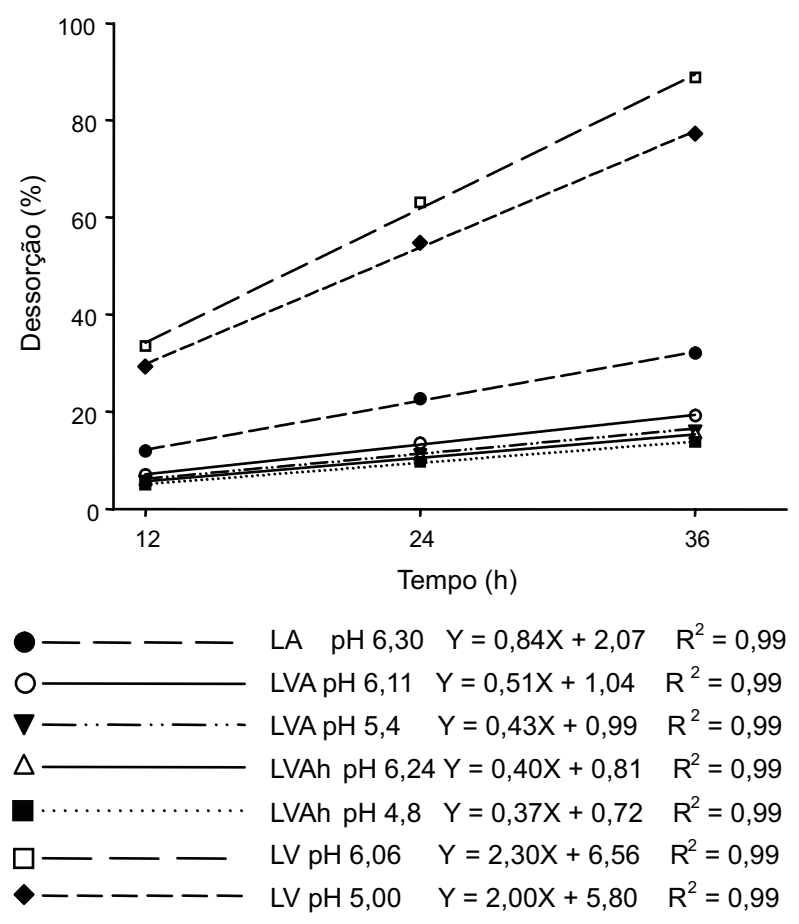

Figura 3 - Porcentagens de dessorção de ametryn em Latossolo Vermelho-Amarelo (LVA), Latossolo Vermelho-Amarelo húmico (LVAh), Latossolo Vermelho (LV) e Latossolo Amarelo (LA), com diferentes valores de $\mathrm{pH}$. 
Ao se comparar a dessorção nos solos com e sem correção de $\mathrm{pH}$, verificou-se a influência dessa característica do solo no processo dessortivo. Solos submetidos à correção de $\mathrm{pH}$ apresentaram porcentagens de dessorção maiores que quando avaliados em seu $\mathrm{pH}$ natural, indicando maiores riscos ambientais. Andrade et al. (2010) estudaram o processo dessortivo em Latossolo Vermelho-Amarelo com diferentes valores de $\mathrm{pH}$ e observaram que os solos com maiores valores de $\mathrm{pH}$ apresentaram menor sorção, evidenciando que o aumento do $\mathrm{pH}$ do meio provoca a diminuição da quantidade do ametryn na forma protonada, o que reduz as possibilidades de sorção do herbicida aos coloides do solo. Dessa forma, um processo de calagem do solo pode interferir na disponibilidade do ametryn e influenciar no controle das plantas daninhas, na persistência e no potencial de acumulação em águas subterrâneas.

A equação de Freundlich modificada, como proposta por Carmo et al. (2000), mostrou-se adequada na interpretação do processo de sorção, uma vez que forneceu informações coerentes com as de outros trabalhos realizados com o ametryn e também com herbicidas pertencentes ao mesmo grupo (Vivian et al., 2007; Cao et al., 2008; Flores et al., 2009; Andrade et al., 2010).

Conclui-se que a variação na capacidade sortiva e dessortiva do ametryn observada nos solos avaliados está relacionada aos diferentes teores de matéria orgânica apresentados por eles. Os solos com maiores teores de matéria orgânica foram os que exibiram as menores porcentagens de dessorção, indicando a ocorrência de histerese. Além disso, a correção do $\mathrm{pH}$ pode alterar a capacidade sortiva do solo e, portanto, os processos dependentes da retenção dos herbicidas no solo, ou seja, a degradação e a lixiviação dessas substâncias. Os resultados deste estudo evidenciaram o risco de contaminação ambiental por ametryn e reafirmaram a importância de monitorar o comportamento desse composto no ambiente.

\section{LITERATURA CITADA}

AKMA N. M. H. et al. Sorption-desorption study of a herbicide 2,4-dichlorophenoxyacetic acid on acidic tropical Soils. Malays. J. Soil Sci., v. 13, n. 1, p. 119-131, 2009.
ALBUQUERQUE, M. A. et al. Mineralização e sorção de atrazina em latossolo roxo sob cultivo convencional e plantio direto. R. Bras. Ci. Solo, v. 25, n. 1, p. 179-188, 2001.

ANDRADE, S. R. B. et al. Sorção e dessorção do ametryn em Argissolo Vermelho-Amarelo e Latossolo Vermelho-Amarelo com diferentes valores de $\mathrm{pH}$. Planta Daninha, v. 28, n. 1, p. 177-184, 2010.

BOWMAN, B. T. Conversion of Freundlich adsorption K values to the mole fraction format and the use of $\mathrm{S}_{\mathrm{Y}}$ values to express relative adsorption of pesticides. Soil Sci. Soc. Am. J., v. 46, n. 4, p. 740-743, 1982.

$\mathrm{CAO}$, J. et al. Effects of SOM, surfactant and $\mathrm{pH}$ on the sorption-desorption and mobility of prometryne in soils. Chemosphere, v. 70, p. 2127-2134, 2008.

CARMO, A. M. et al. Sorption of hydrophobic organic compounds by soil materials: application of unit equivalent Freundlich coefficients. Environ. Sci. Technol., v. 34, n. 20, p. $4363-4369,2000$

CARVALHO, F. T. et al. Controle de dez espécies daninhas em cana-de-açúcar com o herbicida mesotrione em mistura com ametryn e metribuzin. Planta Daninha, v. 28, n. 3, p. 585-590, 2010.

CHEFETZ, B. et al. Sorption-desorption behavior of triazine and phenylurea herbicides in Kishon river sediments. Water Res., v. 38, p. 4383-4394, 2004.

CHIOU, C. T. et al. Sorption of selected organic compounds from water to a peat soil and its humic-acid and humin fractions: potential sources of the sorption nonlinearity. Environ. Sci. Technol., v. 34, n. 7, p. 1254-1258, 2000.

DICK, D. P. Matéria orgânica em quatro tipos de solos brasileiros: composição química e sorção de atrazina. Química Nova, v. 33, n. 1, p. 14-19, 2010.

FALONE, S. Z.; VIEIRA, E. M. Adsorção/dessorção do explosivo tetril em turfa e em Argissolo Vermelho-Amarelo. Química Nova, v. 27, n. 6, p. 849-854, 2004.

FERRI, M. V. W. et al. Sorção do herbicida acetochlor em amostras de solo, ácidos húmicos e huminas de Argissolo submetido à semeadura direta e ao preparo convencional. $\mathbf{R}$. Bras. Ci. Solo, v. 29, n. 5, p. 705-714, 2005.

FLORES, C. et al. Adsorption studies of the herbicide simazine in agricultural soils of the Aconcagua valley, central Chile. Chemosphere, v. 74, p. 1544-1549, 2009.

HERWIG, U. et al. Physicochemical interactions between atrazine and clay minerals. Appl. Clay Sci., v. 18, n. 5-6, p. 201-222, 2001.

Planta Daninha, Viçosa-MG, v. 30, n. 3, p. 633-640, 2012 
KOSKINEN, W. C. et al. Sorption-desorption of flucarbazone and propoxycarbazone and their benzenesulfonamide and triazolinone metabolites in two soils Pest Manag. Sci., v. 62, p. 598-602, 2006.

LOVELL, S. T. Hydrolysis and soil adsorption of the labile herbicide isoxaflutole. Environ. Sci. Technol., v. 34, n. 15, p. $3186-3190,2000$

McDONALD, L. Pesticide mobility on a hillside soil in St. Lucia. Agric. Ecosyst. Environ.. v. 72, ?n. ?, p. 181-188, 1999.

NGUYEN, T. et al. Sorption nonlinearity for organic contaminants with diesel soot: method development and isotherm interpretation. Environ. Sci. Technol., v. 38, n. 13, p. $3595-3603,2004$

ORGANIZATION FOR ECONOMIC CO-OPERATION AND DEVELOPMENT - OECD. Guidelines for testing of chemicals, adsorption, 106. Paris: OECD, 2000.

OLIVEIRA, A. R.; FREITAS S. P. Palha de cana-de-açúcar associada ao herbicida trifloxysulfuron sodium + ametryn no controle de Rottboellia exaltata. Bragantia, v. 68, n. 1, p. 187-194, 2009.

OLIVEIRA Jr, R. S. et al. Sorption and leaching potential of herbicides on brazilian soils. Weed Res., v. 41, n. 2, p. $97-110,2001$
RODRIGUES, B. N.; ALMEIDA, F. S. Guia de herbicidas. 5.ed. Londrina: 2005. 592 p.

ROSSI, C. V. S. et al. Mobilidade do sulfentrazone em Latossolo Vermelho e em chernossolo. Planta Daninha, v. 23 , n. 4 , p. $701-710,2005$.

SHENG, G. et al. Influence of $\mathrm{pH}$ on pesticide sorption by soil containing wheat residue-derived char. Environ. Poll., v. 134 , n. 3 , p. $457-463,2005$.

TANG, Z. et al. Adsorption and desorption characteristics of monosulfuron in chinese soils. J. Hazardous Mat., v. 166, n. 2 3, p. 1351-1356, 2009.

VIVIAN, R. et al. Adsorção e dessorção de trifloxysulfuronsodium e ametryn em solos brasileiros. Planta Daninha, v. 25, n. 1, p. 97-109, 2007.

WANG, G. et al. Sorption/desorption reversibility of phenanthrene in soils and carbonaceous materials. Environ. Sci. Technol., v. 41, n. 4, p. 1186-1193, 2007.

WAUCHOPE, R. D. et al. Review: Pesticide soil sorption parameters: theory, measurement, uses, limitations and reliability. Pest Manag. Sci., v. 58, n. 5, p. 419-445, 2002 . 